\title{
LONG-TERM RISE OF STORMINESS OF THE BALTIC SEA NEAR POLAND; POSSIBLE ORIGIN AND CONSEQUENCES
}

\author{
Grzegorz Różyński and Zbigniew Pruszak ${ }^{1}$
}

\begin{abstract}
Long-term growth of storminess of the Baltic Sea near Poland has been identified for autumn and winter months, particularly for January. This growth is concurrent with the increase of westerly waves in Jan., Feb. and Oct. A vivid relationship between the North Atlantic Oscillation and significant wave height $H_{s}$ in Jan. suggests it can be a potential driver of storminess growth in that month. For Feb. this relationship is unstable; other months demonstrate no connection toward the NAO. The wave climate in January also exhibits a strong 8-year cycle, very likely to drive 8 -year variations of shoreline position, detected previously at a study site. The influence of NAO may manifest an unfavorable regime change in which mightier winter storms will be mostly occurring above freezing in the absence of ice cover. Without that cover vulnerable sandy beaches will be exposed to accelerated erosion from direct and stronger wave attack.
\end{abstract}

Keywords: Baltic Sea, storminess, climate change, beach erosion

\section{INTRODUCTION}

The Baltic Sea is almost a land-locked, non-tidal and shallow basin, see Fig. 1, with the area $S=415,000 \mathrm{~km}^{2}$ and volume $V=21,700 \mathrm{~km}^{3}$ (including Kattegat), BACC, 2008. It is very dynamic and strongly influenced by large-scale atmospheric circulation, hydrological processes as well as by the restricted water exchange through the narrow entrance area. The first reconstructions of wave climate there were based on the parametric models, fed by stationary and homogeneous wind inputs, Paszkiewicz, 1988, Zeidler et al., 1995. Next, the so called $2^{\text {nd }}$ generation wave models were applied, Blomgren et al., 2001, Gayer et al., 1995 or Jönsson et al., 2002. The availability of wind fields over the Baltic Sea allowed for $3^{\text {rd }}$ generation WAM4 model to be applied, WAMDI group, 1988. Finally, global meteorological re-analyses provided an input for long-term reconstruction of wave fields of the whole Baltic Sea for the 1958-2001 period with high resolution and precision. The reconstruction procedure is described by Weisse et al., 2009 and presented schematically in Fig. 2. The computed wave climate parameters comprise hourly estimates of significant wave and swell height, wave and swell direction, wind direction and wave period. The reconstructed waves were validated against the available records of actual wave measurements near the study site at Lubiatowo, Poland, Cieślikiewicz and Paplińska-Swerpel, 2005. The validation showed a good agreement between measurements and hindcasts; the correlation coefficient between the hindcast and measured in-situ significant wave height $H_{s}$ equaled 0.82 .

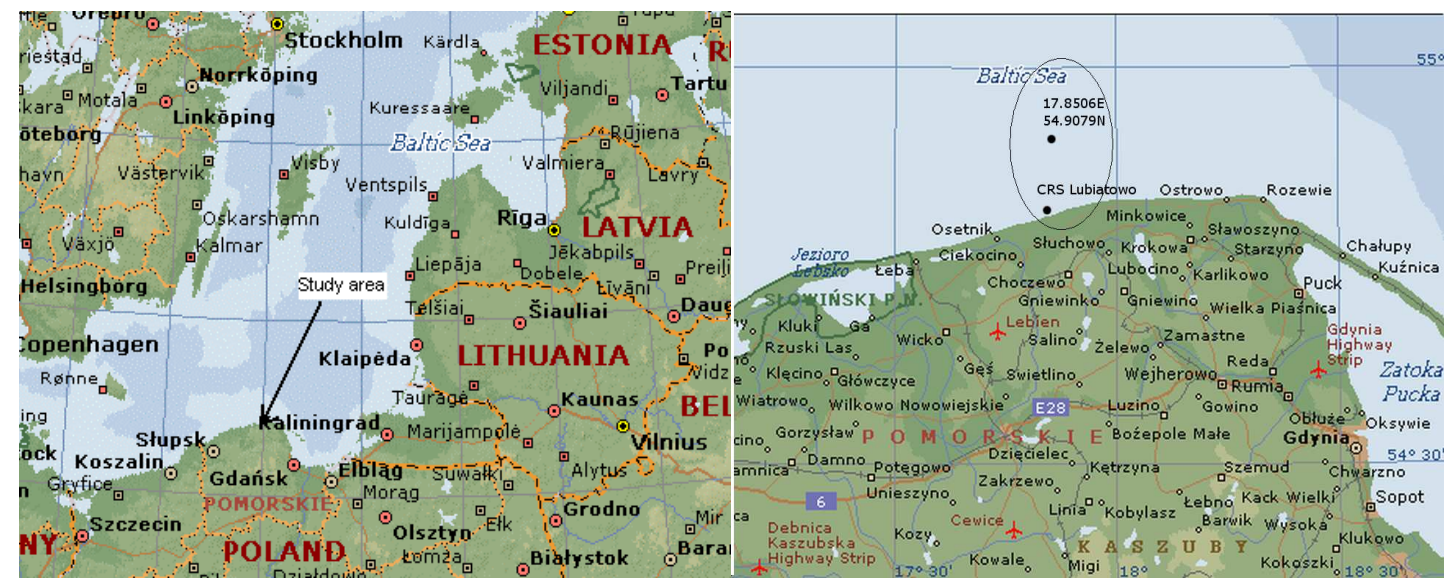

Figure 1. Study area: Baltic Sea (left) and geographic coordinates of reconstruction of deepwater significant wave height near Lubiatowo, PL (right).

${ }^{1}$ Dept. Coastal Engineering \& Dynamics, Inst. Hydro-Engineering, Polish Acad. Sci., 7 Kościerska, 80-328 Gdańsk, Poland 
The general purpose of the study was concentrated on identification of the variability of storminess near Lubiatowo between 1958 and 2001. Secondly, long-term periodic, hydrodynamic forcing patterns were sought to explain peculiar long-term shoreline behavior in the form of shoreline standing waves, identified by Różyński, 2005.

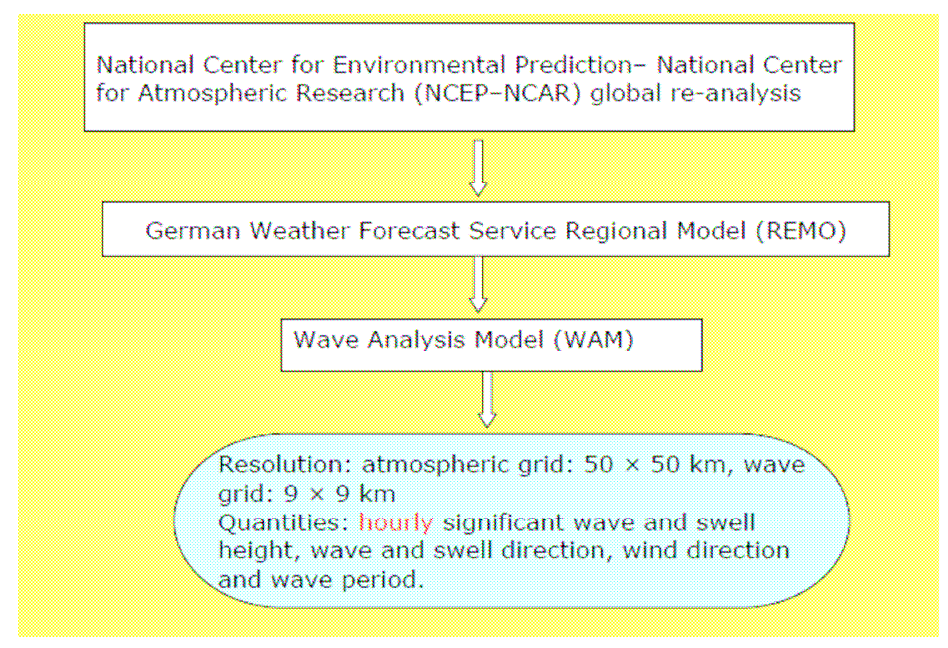

Figure 2. Schematic flow chart of wave climate reconstruction algorithm.

\section{STUDY AREA}

The Coastal Research Station (CRS) of the Institute of Hydro-Engineering is a facility where geodetically referenced long-term morphodynamic data have been collected since 1983 (shoreline positions) and 1987 (seabed records of nearshore bathymetry). The Station is located at Lubiatowo, Poland, facing the southern part of the Baltic Sea (see Figs. 1, 3). The beach there is highly dissipative with multiple (predominantly four) longshore bars and a mild mean slope of $m=\tan \alpha=1-1.5 \%$ with a median grain size of $D_{50}=0.22 \mathrm{~mm}$, Fig. 4 (left). Significant seabed variability can be visible beyond 1,300 m offshore. Although the measurements indicate long-term beach equilibrium, the shoreline is not a perfectly stable feature. The surveys are attached to a local geodetic system, see Fig. 4 (right), so all measurements taken at different times and along different lines are fully consistent. In total, the surveyed area covers 2,600m of alongshore distance with 27 cross-shore profiles uniformly spaced at $100 \mathrm{~m}$. Enumeration of these profiles is explained in Fig. 4 (right) and reflects the history of geodetic base at Lubiatowo ( 8 profiles were fixed first, the remaining ones were added later). The shoreline position data represent 16 years of measurements, Fig.5. Surveys started on $22^{\text {nd }}$ Sept. 1983 and typically have been repeated every four weeks (28 days); the last survey included in this study was carried out on $2^{\text {nd }}$ Sept. 1999. This data set was extensively analyzed with multi-channel singular spectrum analysis (MSSA), Różyński, 2005, who detected long-term shoreline standing waves, one with $T=$ several decades and the other with $T=8$ years, Fig. 6 . Their presence gave inspiration for the determination of hydrodynamic patterns with similar periodic characteristics, because in the absence of tides wave-driven hydrodynamics is the only agent able to drive shoreline/seabed variability.
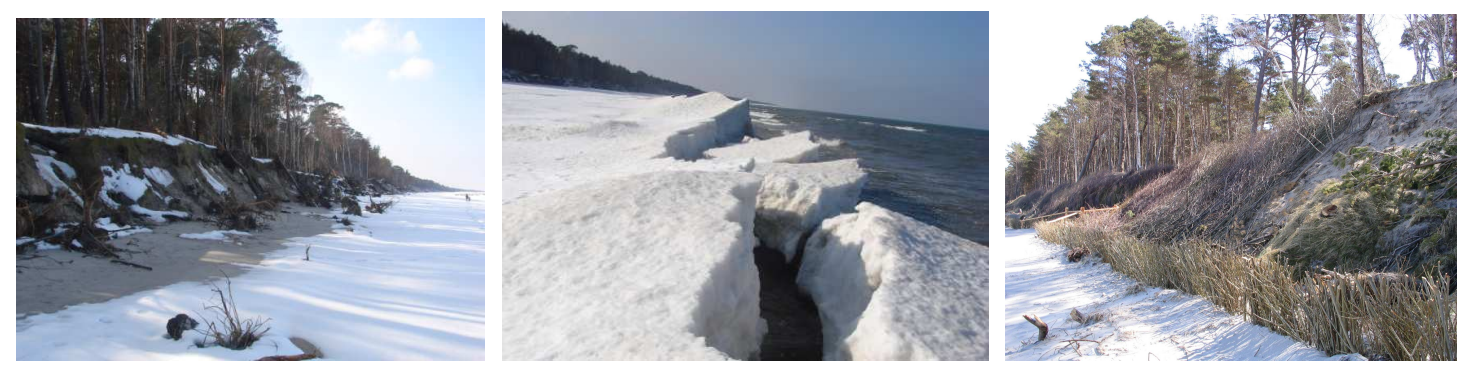

Figure 3. Beach at CRS Lubiatowo: dune erosion after heavy storm, photo: G. Różyński (left), ice barrier preventing further dune erosion, photo: G. Różyński (middle), rehabilitation of dunes with stick fences in spring, photo D. Piotrowska (right). 

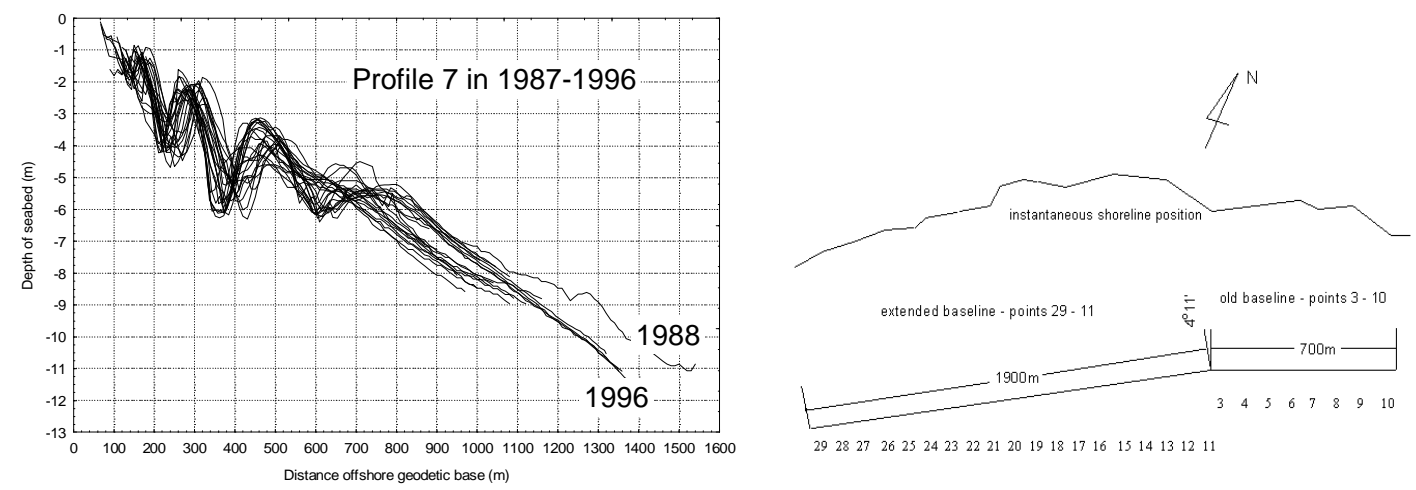

Figure 4. Exemplary multiple bar cross-shore profile evolution at CRS Lubiatowo (left) and local geodetic base with profile line numbers (right).

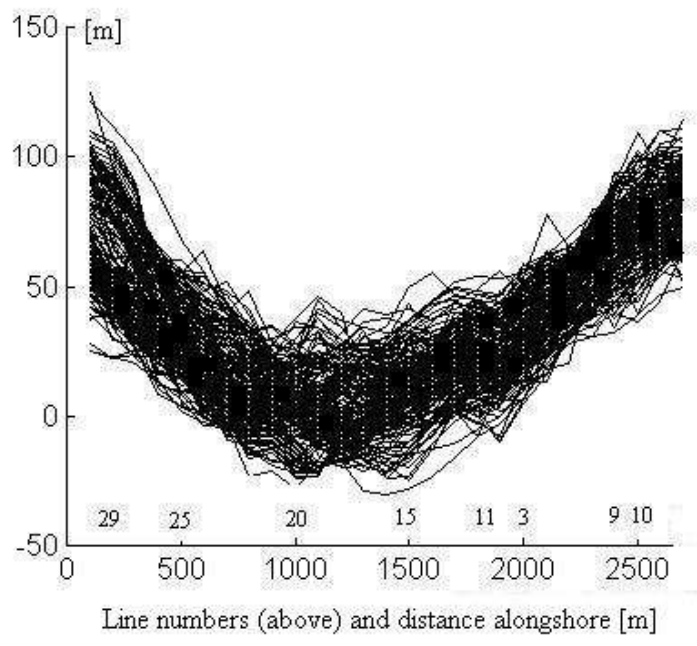

Figure 5. Envelope of shoreline records 1983-1999.
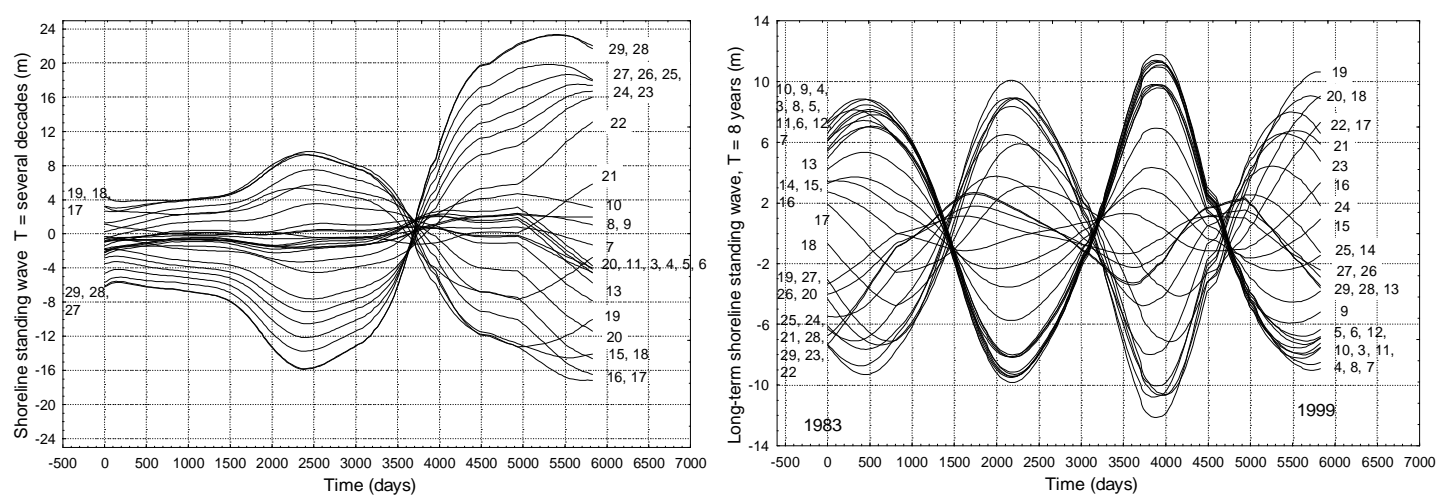

Figure 6. Long-term shoreline standing waves: $T=$ several decades (left) and $T=8$ years (right) - numbers denote profile lines of geodetic base.

\section{ANALYSIS}

The first exercise was the assessment of annual variation of wave climate. To do so mean values of deepwater $H_{s}$ of the point, whose geographic coordinates are plotted in Fig. 1 (right), were computed for all 12 calendar months. They are presented in Fig. 7 and demonstrate a typical Baltic Sea seasonal pattern. The most energetic are winter months of January, February, November and December. For Jan. Nov. and Dec. the average $H_{s}$ gently exceeds $1 \mathrm{~m}$, whereas for Feb. it falls slightly below that value. 
The least active period occurs in spring/summer (May, June, July and August), where $H_{s}$ roughly equals $0.6 \mathrm{~m}$. The remaining months represent a passage from winter to summer (March, April) and back (September, October).

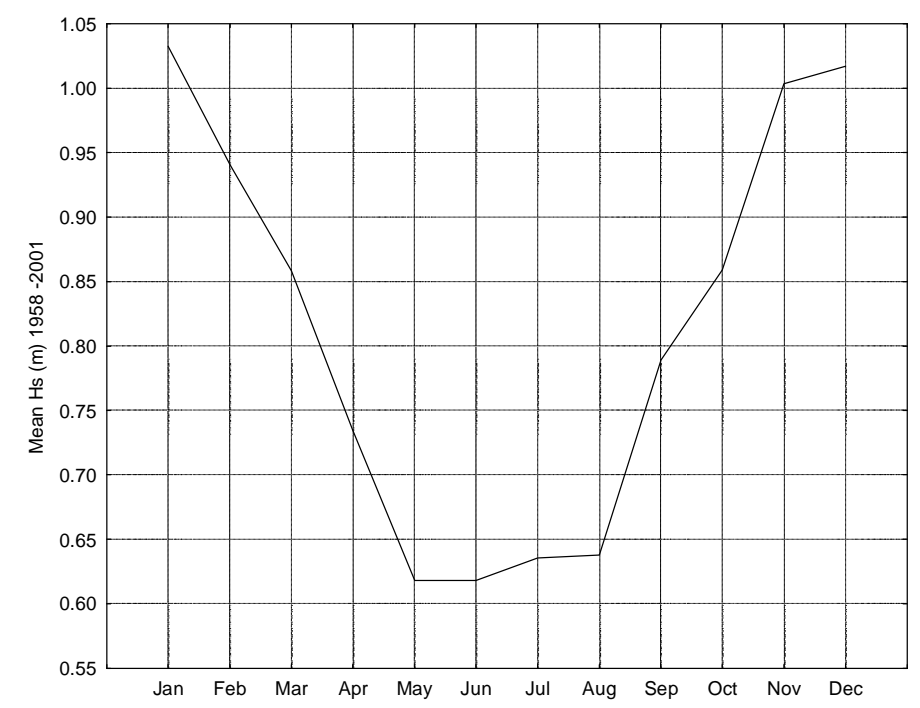

Figure 7. Annual variability of wave climate near Poland expressed through mean $\boldsymbol{H}_{s}$ for $\mathbf{1 2}$ calendar months.

The next element of the study was evaluation of the evolution of storminess. To that end the whole data was divided into two halves. One of them covered the time between 1958 and 1979 and the other accounted for the 1980-2001 period. A threshold $H_{s}>1 \mathrm{~m}$ was chosen and the number of hours above that value in each month was counted for both halves. The results are plotted in Fig. 8. We can immediately see a spectacular growth of storminess for Jan.; since the threshold $H_{s}$ in that month was exceeded a little more than 5,000 hours in the former sub-period vs. more than 8,000 hours in the latter. A certain growth of storminess is also discernible for Feb. Oct. Nov. and Dec. For Feb. and Oct. this change may bear some (limited) importance, whereas for Nov. and Dec. it looks insignificant.

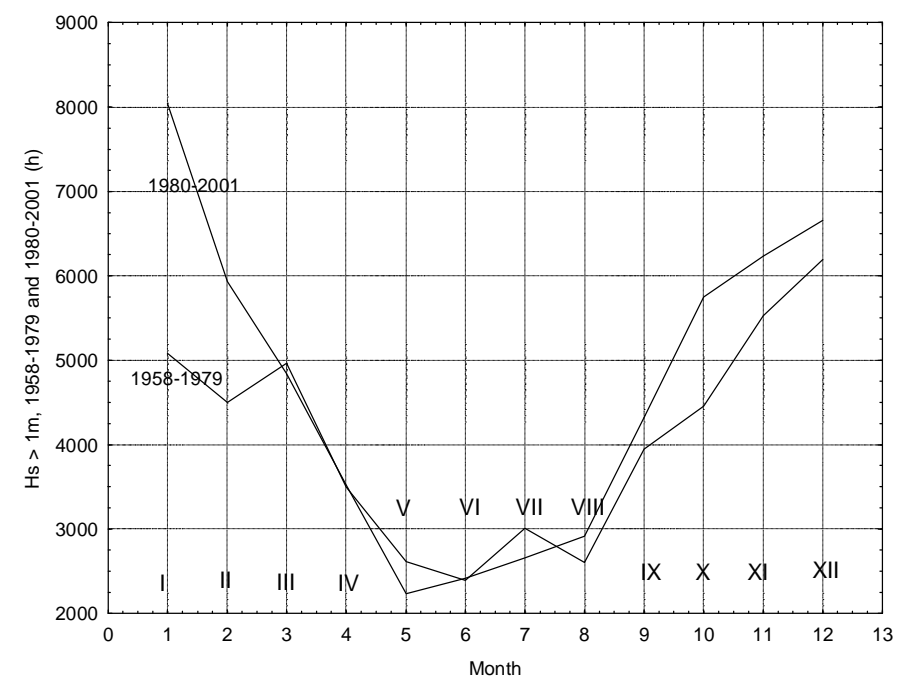

Figure 8. Number of hours for $H_{s}>1 \mathrm{~m}$ for calendar months: 1958-1979 (blue) and 1980-2001 (red).

Further insight into potential drivers of increased storminess was endeavored by plotting empirical probability density functions of wave directions for months where non-trivial growth of storminess had been identified (Jan., Feb., Oct.). Again a threshold $H_{s}>1 \mathrm{~m}$ was chosen i.e. the empirical distributions correspond to stormy events. They are plotted in Fig. 9. The January plot reveals an increase of waves 
coming from $\mathrm{W}$ in the $2^{\text {nd }}$ sub-period (1980-2001) at the expense of waves from mostly the $\mathrm{N}$ sector. Also NE and E waves demonstrate a slightly lower rate of occurrence in Jan. Importantly, NW waves did not change their rate of occurrence in that month. For February we can see a similar increase of westerly waves, compensated by less frequent occurrences of NW waves. Also in October the growth of westerly waves is significant, being compensated evenly by less frequent occurrences of waves from $\mathrm{NW}, \mathrm{N}, \mathrm{NE}$ and $\mathrm{E}$.
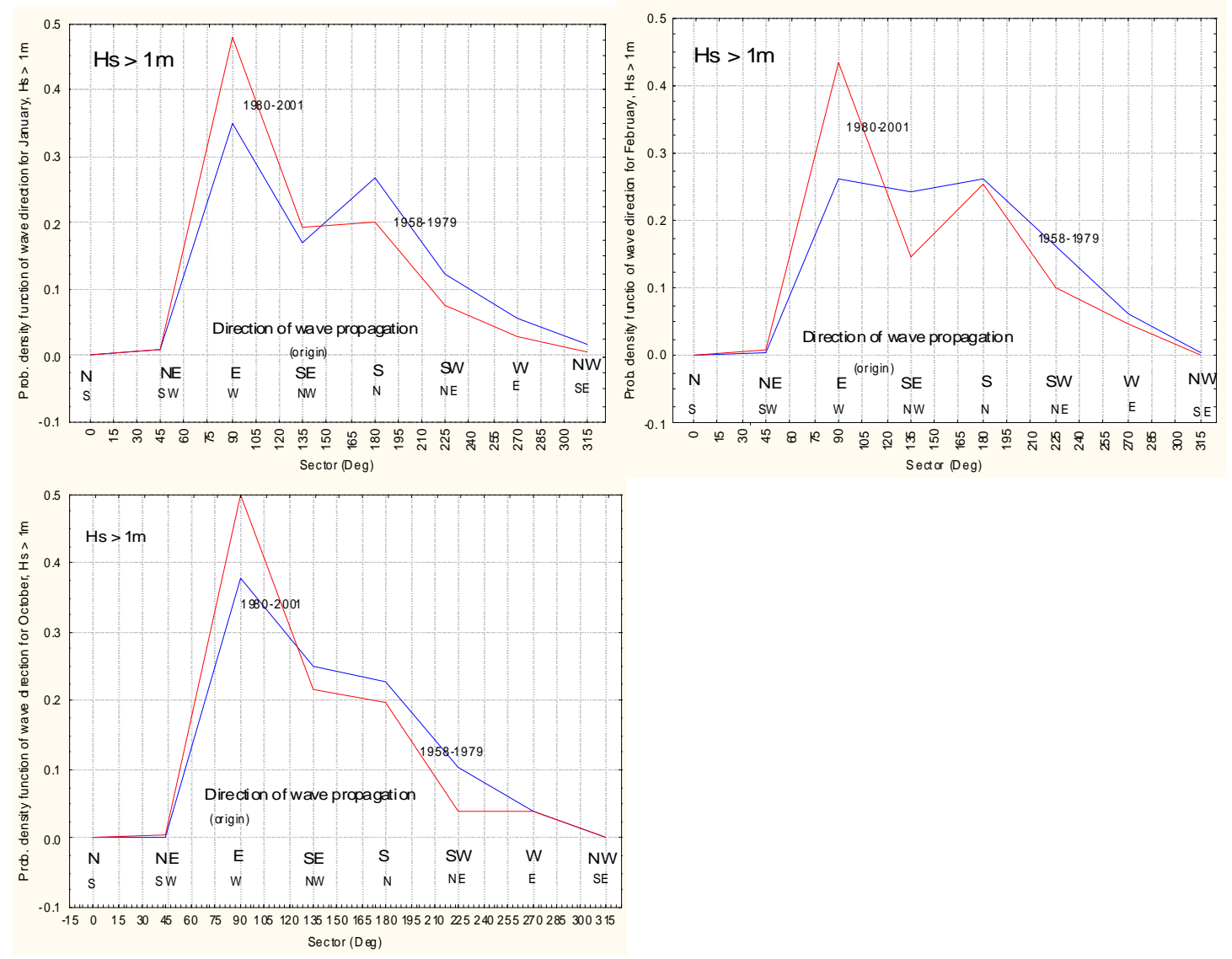

Figure 9. Change of wave direction during storms in Jan. (top left), Feb. (top right) and Oct. (bottom) for 1958-1979 (blue) vs. 1980-2001 (red).

The growth of westerly waves may indicate a coupling between wave climate in the Baltic Sea and global meteorological patterns over the Atlantic. Interestingly, such (long-term) couplings were identified by a number of researchers for seawater level at several locations in the Baltic Sea and the North Atlantic Oscillation index (NAO). For example Johansson et al., 2001, 2004 found an association between the annual NAO index and the mean sea level near Helsinki, Finland. Andersson, 2002 documented the connection of the sea level data for Stockholm, Sweden and the winter NAO index. A non-trivial correlation for the atmospheric circulation and sea level was also found for the Estonian coast, where higher westerly wind indices, including NAO effects, were found responsible for higher sea levels, especially during winter months, Suursaar et al., 2006. Andersson, 2002 and Janssen, 2002 in their studies on sea level variations found time-varying correlations, whose maxima occurred near the end of time series they examined; the former for the 1825-1997 and the latter for 1890-1993. They concluded that the growth of correlation indicates an increased potential of winter NAO index (NAOWI) for controlling the regimes of physical processes in the Baltic Sea during winters.

To examine the NAO as a driver of increased storminess, normalized monthly NAO indices for Jan., Feb. and Oct., provided by National Oceanic and Atmospheric Administration (NOAA) for the 1950-2006 period, were confronted with time series of mean monthly $H_{s}$ for those months. The NAO $H_{s}$ pairs for those months, are shown in Fig. 10. 

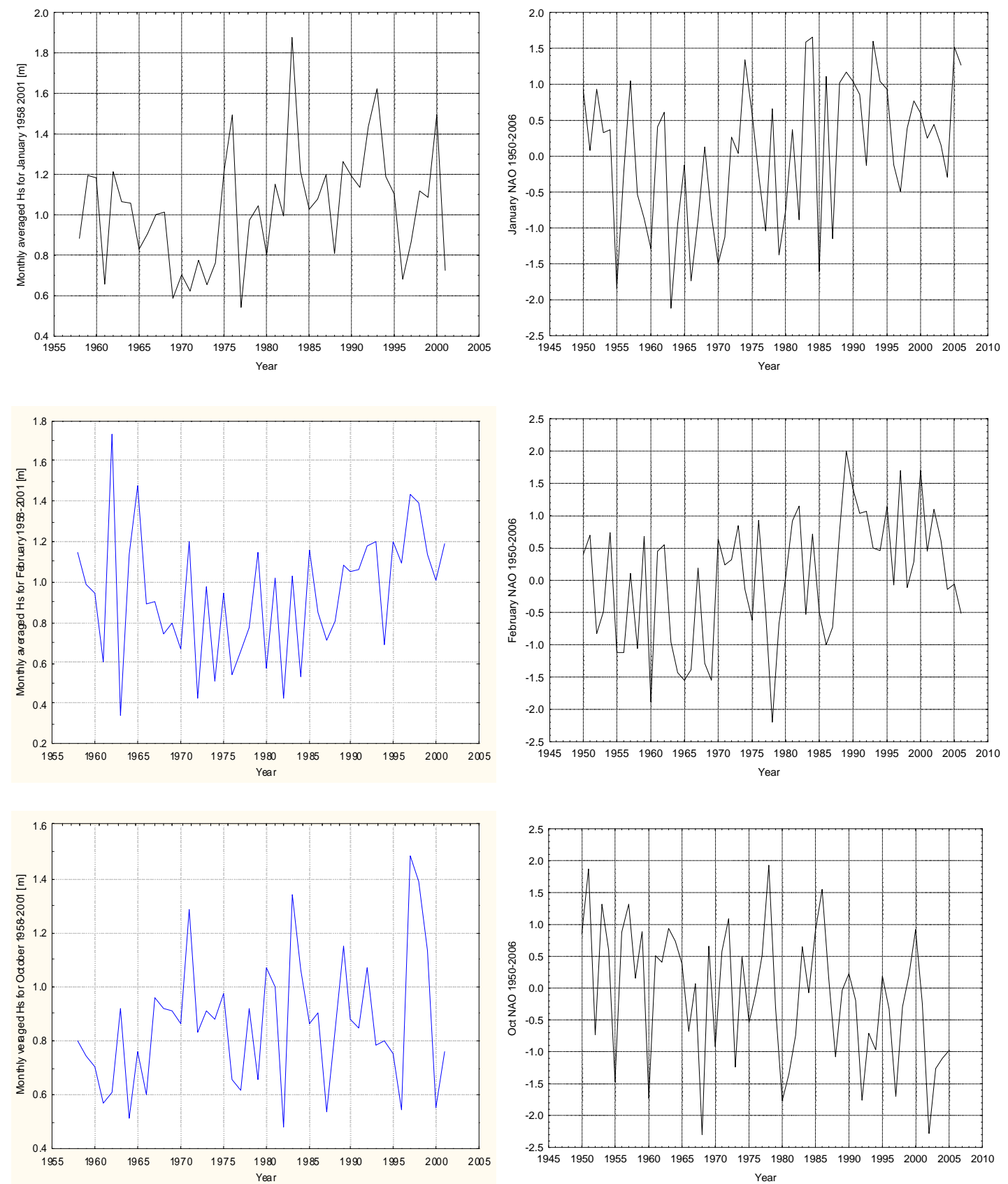

Figure 10. Time series of $\boldsymbol{H}_{s}$ (left) and NAO (right) for Jan. (top), Feb. (middle) and Oct. (bottom).

The inspection of Fig. 10 immediately shows that no connection between the NAO and $H_{s}$ can exist in October, because a clearly visible growing global trend of $H_{s}$ is concurrent with a falling October NAO trend. Hence, the growth of storminess in October must be brought about by other, not yet identified global phenomena and processes. By contrast the $H_{s}$ - NAO pairs in Jan. and Feb. show similar global long-term behavior (growth), so their coupling is possible. Therefore, further inspection of both time series pairs was done by means of classical spectral analysis. Fig. 11 shows $H_{s}-$ NAO periodogram pairs, which exhibit coincidence of low-frequency behavior - most likely similarities of long-term trends. Moreover, the Jan. periodogram of $H_{s}$ exhibits a strong spectral peak with $T=8$ years, corresponding to the shoreline standing wave with the same period, identified in 2005 and plotted in Fig. 6 (right). The lack of such a peak in the January NAO periodogram shows that the NAO cannot be accounted for this hydrodynamic cycle. Still, the coincidence of long-term trends and the presence of 8- 
year hydrodynamic oscillation in January wave climate revealed the necessity of further more in-depth signal processing analysis.
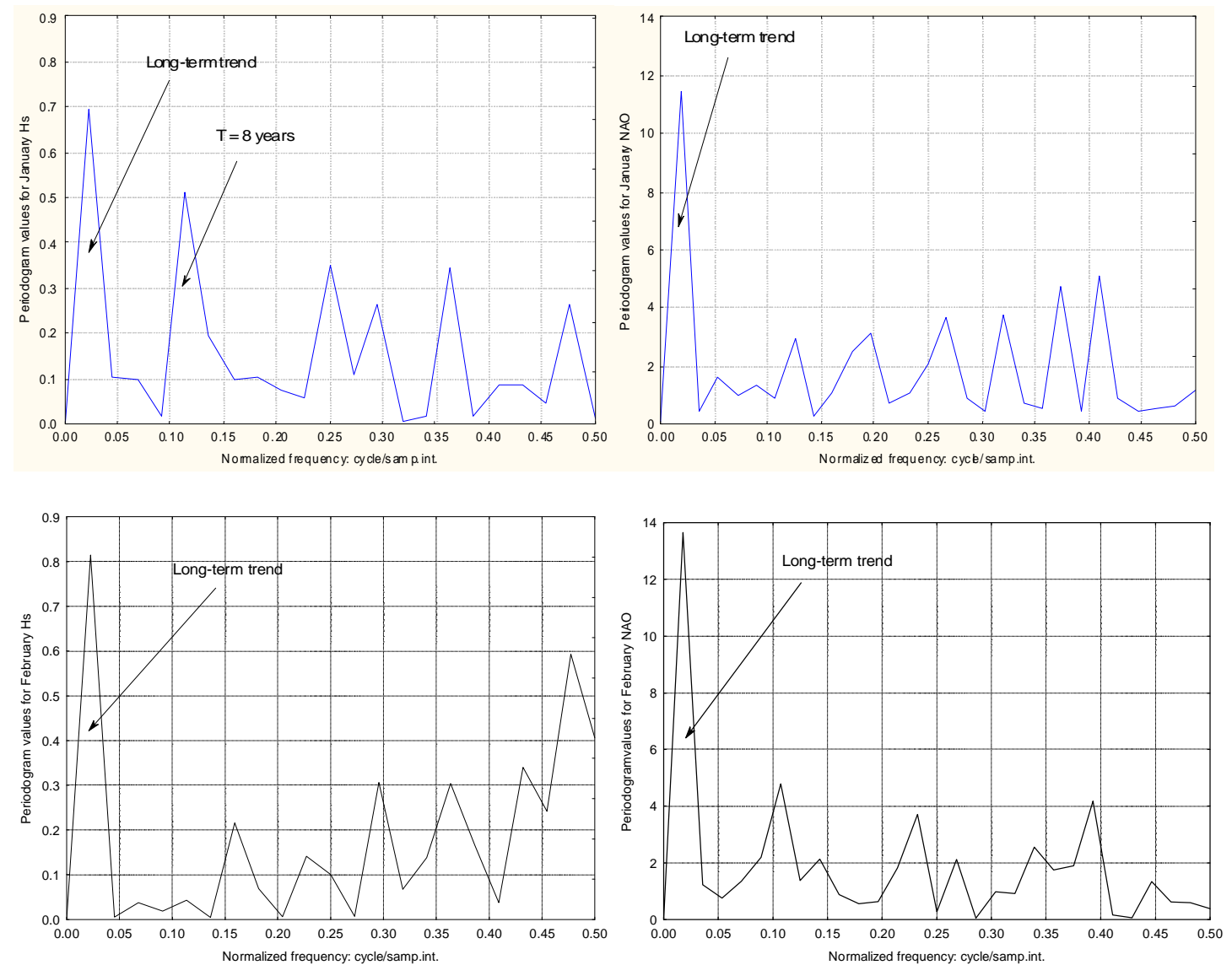

Figure 11. Periodograms of $H_{s}$ (left) and NAO (right) for Jan. (top) and Feb. (bottom).

The tool applied was Singular Spectrum Analysis (SSA), whose details can be found at Vautard et al., 1992 or Różyński et al., 2001. This method has proved to be a valuable technique for the extraction of global trends, oscillatory behavior and chaotic patterns from short and noisy time series. Fig. 12 shows normalized to zero mean and unit standard deviation SSA-derived trends of NAO and Hs for Jan. and Feb.
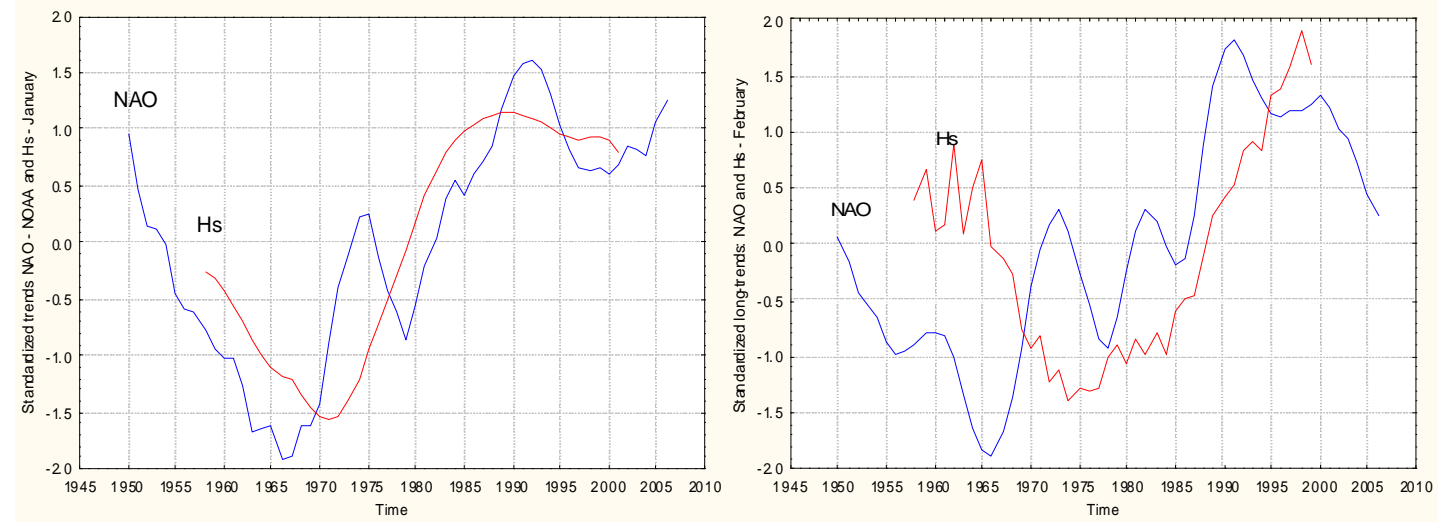

Figure 12. Normalized $H_{s}$ (red) and NAO (blue) long-term trends for January (left) and February (right). 
Fig. 12 demonstrates that in January there is a strong relationship between both trends. The NAO seems to lead $H_{s}$ by about four years; $c f$. NAO minimum in 1967 , followed by $H_{s}$ minimum in 1971 . Then both quantities grew consistently between 1971 and 1990, gently decreased after 1990 and finally stabilized at a relative high normalized value of about 1 . High NAO January index indicates a likelihood of warm (above freezing) and stormier weather - the lasting positive coupling with $H_{s}$. For February the relationship between both trends is much more problematic. The NAO trend reached its minimum in 1967, but it was not until 1976 when the minimum of $H_{s}$ was achieved. After that both trends roughly grew together until 1992. After that year however, the NAO index began a rapid decrease, whereas $H_{s}$ continued to grow until 1998. Thus, the relationship between both trends looks intermittent and vague. The strong January relationship and much weaker one in February are confirmed by Fig. 13, where linear regression between long term trends is presented; high correlation coefficient of that regression in January $(R=0.7)$ corresponds to a considerably lower one in February $(R=0.43)$.
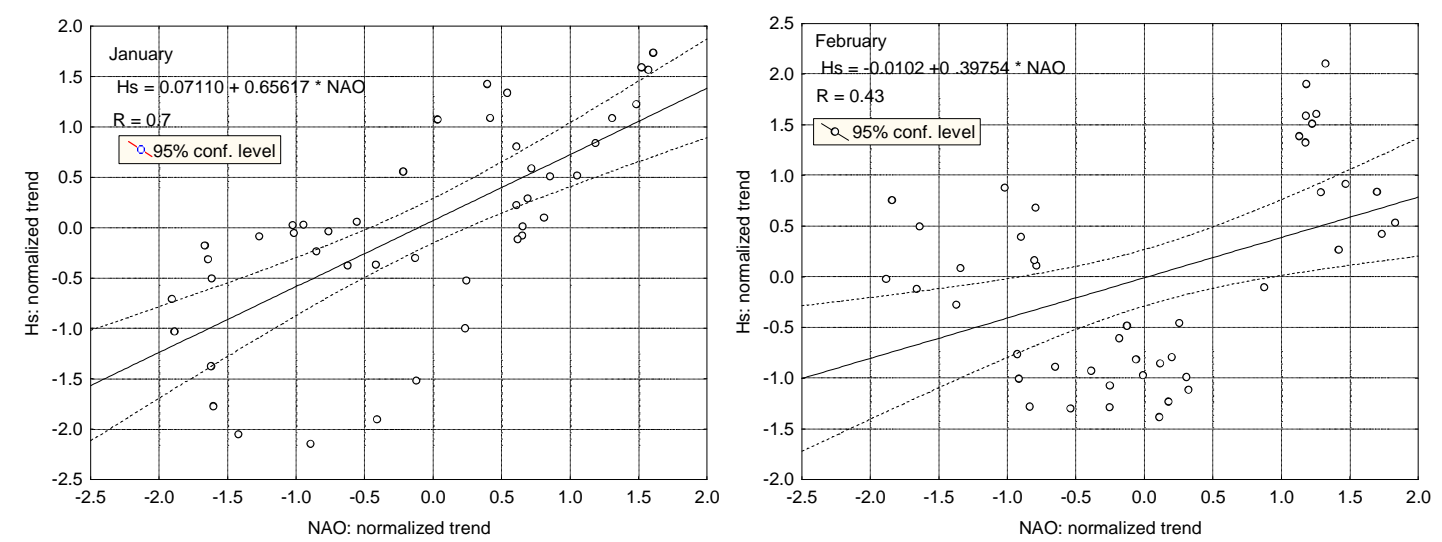

Figure 13. Linear regression between NAO and $H_{s}$ for Jan. (left) and Feb. (right).

In all the strong NAO $-H_{s}$ connection in January and the delicate one in February suggest that in January Baltic Sea wave climate falls under certain control of global meteorological patterns developing over the Atlantic Ocean. This control is not persistent though and already in February it begins to disappear. After that interdependence between the NAO and wave climate is broken off: further research is needed to identify major drivers of hydrodynamic regimes in the Baltic Sea in spring, summer and autumn.

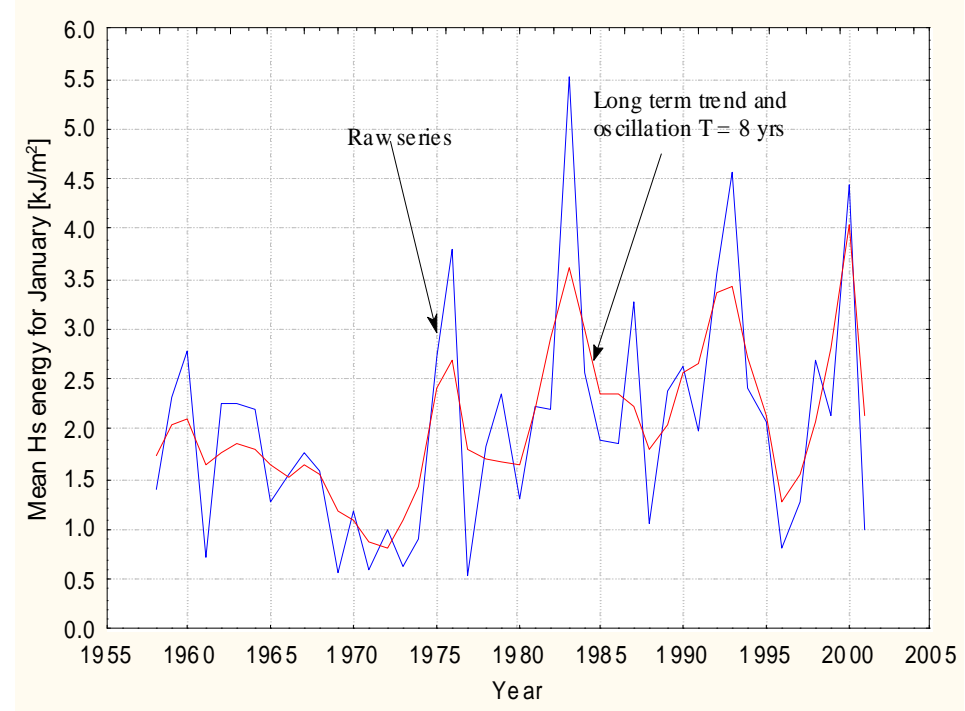

Figure 14. Time series of average significant wave energy in January (blue) and sum of key SSA components (red). 
As was shown in Fig. 11, top left, the periodogram of $H_{s}$ for January contains a significant peak, whose period $T=8$ years corresponds to the shoreline standing wave. The importance of that peak is presented in Fig. 14, where average significant wave energy in January (blue line) is presented together with SSA extracted sum of key components (red line). It can be seen that since 1975 a persistent 8-year (hydrodynamic) oscillation developed. It is particularly visible in wave energy plots, such as the one in Fig. 14 because of quadratic dependence between $H_{s}$ and wave energy. High variation of energy fluxes is also well documented in Table 1, where we can see energy inputs in extreme years together with their ratios.

\begin{tabular}{|l|c|c|c|c|c|c|}
\hline \multicolumn{7}{|c|}{ Table 1. Wave energy flux extremes in Januaries } \\
\hline $\begin{array}{l}\text { Time } \\
\text { between } \\
\text { extremes }\end{array}$ & $\begin{array}{l}\text { Max } \\
\text { total } \\
\text { peak } \\
\text { energy }\end{array}$ & $\begin{array}{l}\text { Min } \\
\text { total } \\
\text { peak } \\
\text { energy }\end{array}$ & $\begin{array}{l}\text { Max/Min } \\
\text { total }\end{array}$ & $\begin{array}{l}\text { Max peak energy key } \\
\text { SSA components }\end{array}$ & $\begin{array}{l}\text { Min peak energy key } \\
\text { SSA components }\end{array}$ & $\begin{array}{l}\text { Max/Min } \\
\text { SSA }\end{array}$ \\
\hline- & $\mathrm{kJ} / \mathrm{m}^{2}$ & $\mathrm{~kJ} / \mathrm{m}^{2}$ & - & $\mathrm{kJ} / \mathrm{m}^{2}$ & $\mathrm{~kJ} / \mathrm{m}^{2}$ & - \\
\hline $\begin{array}{l}1976-1980 \\
(\mathrm{max} / \mathrm{min})\end{array}$ & 3.80 & 1.30 & 2.92 & 2.68 & 1.65 & 1.62 \\
$\begin{array}{l}1980-1983 \\
\text { (min/max) }\end{array}$ & 5.33 & 1.30 & 4.10 & 3.60 & 1.65 & 2.18 \\
$\begin{array}{l}1983-1988 \\
(\mathrm{max} / \mathrm{min}) \\
\begin{array}{l}1988-1993 \\
(\mathrm{~min} / \mathrm{max})\end{array}\end{array}$ & 5.33 & 1.07 & 4.98 & 3.60 & 1.79 & 2.01 \\
$\begin{array}{l}1993-1996 \\
\text { (max/min) }\end{array}$ & 4.56 & 0.82 & 5.56 & 3.43 & 1.79 & 1.92 \\
$\begin{array}{l}1996-2000 \\
(\mathrm{~min} / \mathrm{max})\end{array}$ & 4.44 & 0.82 & 5.41 & 3.43 & 1.26 & 2.72 \\
\hline
\end{tabular}

The detection of 8-year oscillation in January wave climate can provide a credible explanation for the existence of shoreline standing wave with the same period. First, due to the absence of tides, the whole beach is wave-dominated, so there are no other drivers of shoreline change but wave-driven hydrodynamics. Next, the beach exhibits long-term stability (equilibrium between erosion and accretion), so the 8 - year shoreline standing wave can be understood as adoption of the beach to varying energy fluxes. Finally, this cycle occurs in the most energetic month, so substantial changes in energy input between extreme Januaries are very likely to remain imprinted in the shoreline evolution.

\section{CONCLUSIONS}

The analysis of long-term wave climate hindcast can be summarized as follows:

1. Baltic Sea has been experiencing the growth of storminess in winter over the last decades. It is particularly spectacular for January, also in February and October this growth is notable. For November and December it is still discernible but appears barely significant - see Fig. 8 .

2. Baltic Sea has been also experiencing the growth of westerly waves during extreme events in January, February and October. This and the previous conclusion point to the influence of global meteorological patterns developing over the Atlantic Ocean.

3. Time series of monthly indices of North Atlantic Oscillation were confronted with the hindcast time series of monthly mean values of significant wave height to seek potential couplings. Divergent trajectories of the October NAO $-H_{s}$ pair revealed no such relationship can exist in that month. However, classical spectral analysis identified similarities of low frequency behavior (trends) in January and February in both NAO and $H_{s}$. Thus, using Singular Spectrum Analysis (SSA) a non-trivial coupling was identified for January. For February though the coupling is intermittent, weaker and appears only between 1976 and 1992. After that time it appears to have broken off.

4. Relatively strong interdependence of NAO and $H_{s}$ in January and stabilization of both normalized trends high above the average value after 1990 suggests a likelihood of more frequent occurrence of stormier and warmer weather. It is bad news for sandy beaches of south Baltic Sea, because warmer temperature will coincide with diminishing of ice cover that provides substantial protection against wave action in winter. Thus, intensification of beach erosion will become one of key issues of coastal zone management in that region.

5. Feeble and unstable relationship of NAO and $H_{s}$ in February and the lack of such couplings in other months indicate that sporadically the Baltic Sea can be controlled to some degree by global 
meteorological patterns developing over the Atlantic. Other global meteorological patterns should be inspected in search of couplings with hydrodynamic regimes of the Baltic Sea. The prime target is the Scandinavia Pattern (SCA), because of its relative proximity to the Baltic Sea area.

6. The periodogram of January $H_{s}$ contains a fairly strong component with $T=8$ years; it is very likely to drive the previously identified shoreline standing waves with the same period, because in January the beach receives the largest annual wave energy input and 8-year hydrodynamic oscillation can and should remain imprinted in long-term shoreline evolution.

7. The presence of 8-year shoreline standing wave can also be explained as a response of the stable beach to the variations of wave energy flux. Stability of the beach requires a neutral littoral drift (no longshore gradient of sediment transport), so to retain that neutral drift the beach responds developing shoreline standing waves, whose period is coincident with the period of hydrodynamic oscillation.

\section{ACKNOWLEDGMENTS}

The support of the European Commission through FP7.2009-1, Contract 244104 - THESEUS ("Innovative technologies for safer European coasts in a changing climate"), is gratefully acknowledged.

The support of the European Commission through FP7-SPACE-2009-1, Contract 242284 - FIELD_AC ("Fluxes, Interactions and Environment at the Land-Ocean Boundary. Downscaling, Assimilation and Coupling."), is gratefully acknowledged.

\section{REFERENCES}

Andersson, H.C., 2002. Influence of long-term regional and large-scale atmospheric circulation on the Baltic Sea level. Tellus A 54: 76-88.

Blomgren, S., Larson, M. and Hanson, H., 2001. Numerical Modeling of the Wave Climate in the Southern Baltic Sea. Journal of Coastal Research Vol. 17, No.2/2001.

Cieślikiewicz, W., Paplińska-Swerpel, B., 2005. Rekonstrukcja falowania wiatrowego Bałtyku w okresie 1958-2001. Inżynieria Morska i Geotechnika 4/2005, 313-321. ( Reconstruction of Baltic Sea Wind Waves 1958-2001. Marine Engineering and Geotechnics 4/2005, 313-321).

Gayer, G., Günther, H., Winkel, N., 1995. Wave climatology and extreme value analysis for the Baltic Sea off the Warnemünde harbour entrance. Deutsche Hydrographische Zeitschrift 47 (2)/1995. (German Hydrographic Journal 47 (2)/1995).

Janssen, F., 2002. Statistical analysis of multi-year variability of the hydrography in North Sea and in the Baltic Sea. PhD thesis, Univ. of Hamburg.

Johansson, M., Boman, H., Kahma, K.K., Launiainen, J., 2001. Trends in sea level variability in the Baltic Sea. Boreal Env. Res. 6: 159 - 179.

Johansson, M., Kahma, K.K, Boman, H., Launiainen, J., 2004. Scenarios for the sea level on the Finnish coast. Boreal Env. Res. 9: 153 - 166.

Jönsson, A., Broman, B., Rahm, L., 2002. Variations in the Baltic Sea wave fields. Ocean Engineering 20/2002.

Paszkiewicz, Cz., 1988. Falowanie wiatrowe Morza Bałtyckiego. Raport wewn. Akademii Marynarki Wojennej 808/88, Gdynia 1988. (Baltic Sea Wind Waves. Internal Report of the Polish Naval Academy 808/88, Gdynia 1988).

Różyński G., Larson M., Pruszak Z., 2001. Forced and Self-organized Shoreline Response for a Beach in the Southern Baltic Sea Determined through Singular Spectrum Analysis, Coastal Engineering43 (2001), pp. 41-58.

Różyński, G., 2005. Long term shoreline response of a non-tidal, barred coast, Coastal Engineering, 52 (2005), pp 79-91.

Suursaar, Ü., Jaagus, J., Kullas, T., 2006. Past and future changes in sea level near the Estonian coast in relation to changes in wind climate. Boreal Env. Res. 11: 123-142.

The BACC Author Team (2008): Assessment of Climate Change for the Baltic Sea Basin. SpringerVerlag Berlin Heidelberg, ISBN: 978-3-540-72785-9, 473pp.

Vautard, R., Yiou, P., Ghil, M., 1992. Singular spectrum analysis: a toolkit for short, noisy, chaotic signals. Physica D 158, 95-126.

WAMDI Group, 1988. The WAM model—A third generation ocean wave prediction model. J. Phys. Oceanogr., 18, 1776-1810. 
Weisse, R., von Storch, H., Callies, U., Chrastansky, A., Feser, F., Grabeman, I., Günther, H., Pluess, A., Stoye, T., Tellkamp, J., Winterfeldt, J., Woth, K., 2009. Regional Meteorological-Marine Reanalyses and Climate Change Projections. Results for Northern Europe and Potential for Coastal and Offshore Applications. Bull. Amer. Meteor. Soc., Vol. 90, Issue 6, 849-860.

Zeidler, R.B., Wróblewski, A., Miętus, M., Dziadziuszko, Z., 1995. Wind, wave and storm surges regime at the Polish Baltic Coast. Journal of Coastal Research. Special Issue No. 22, 1995. 